\title{
Navigating the Unprecedented: Leading Remotely Unexpectedly ${ }^{1}$
}

\author{
Matthew Sowcik and Megan Stein ${ }^{2}$
}

\section{Introduction}

When a pandemic or disaster happens, it often requires those involved to change the way they perceive the world around them. Leading your team during rapid change and increased complexity is no different. During times of unknown or unprecedented change, leaders must take a step back and reexamine the way they are leading, even if they are feeling high levels of ambiguity and stress. In these situations, leaders tend to rely on a set of assumptions or ideas about how to do their job. As the world moves quickly to social distancing and remote work, leaders are relying on their assumptions to navigate this new landscape. In times of rapid change, relying on set assumptions can provide some comfort in moving forward. Nevertheless, to lead more effectively, especially in a remote-work setting, it is critical that leaders use different frames of reference to address the changing landscape.

Identifying and utilizing different frames are valuable in helping leaders move forward during complex and uncertain times. Different frames of reference can act as a roadmap allowing leaders to take the first steps into the unknown (Sowcik et al., 2017). Four frames (structural, human resource, symbolic, and political) can be used to address different aspects of leadership (Bolman \& Deal, 2013). This article applies these four frames to provide best practices for leading in a remote-work environment.

\section{Structural Frame}

When examining the process of leading remote workers through Bolman and Deal's (2013) structural frame, the focus is on the goals, roles, and formalized relationships found between members of a department or organization. The following best practices allow a leader to address structural elements of leading employees when working remotely.

- Communicate boundaries and guidelines: Providing clear guidelines and boundaries is critical while transitioning to a remote-work environment, for two major reasons. First, as employees move to this format, especially in such a short time frame, confusion and uncertainty are often elevated. By providing clear guidelines, the anxiety an employee feels will be replaced by knowing they have particular deliverables due each day or at the end of the week. Second, setting these clear expectations provides high-performing employees an opportunity to pace themselves and not experience burnout or have resentment. Without the natural break in the day moving from work to home, some employees may continue to work too long (Wingard, 2020). One way to address employees working too long is to discuss the topic during a team meeting. During this time, ask employees about both the space they have designated for working at home and how they can disconnect from their work at the end of the day. Sharing experiences will provide employees

1. This document is AEC691, one of a series of the Department of Agricultural Education and Communication, UF/IFAS Extension. Original publication date March 2020. Visit the EDIS website at https://edis.ifas.ufl.edu for the currently supported version of this publication.

2. Matthew Sowcik, assistant professor, and Megan Stein, lecturer, Department of Agricultural Education and Communication, UF/IFAS Extension, Gainesville, FL 32611.

The Institute of Food and Agricultural Sciences (IFAS) is an Equal Opportunity Institution authorized to provide research, educational information and other services

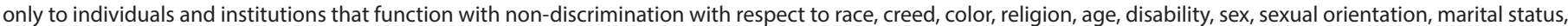

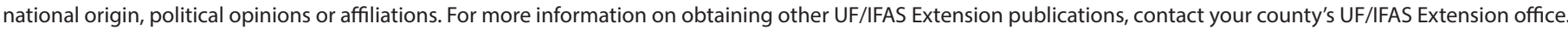
U.S. Department of Agriculture, UF/IFAS Extension Service, University of Florida, IFAS, Florida A \& M University Cooperative Extension Program, and Boards of County Commissioners Cooperating. Nick T. Place, dean for UF/IFAS Extension. 
with good practices and communicate expectations about how long others are working throughout the day.

- Establish clear goals: Now more than ever, clear goals are crucial to proactively address both an employee's anxiety associated with the move to remote work and to alleviate any confusion around expectations, which often leads to stress and a tense work environment (Astashkina, 2005; Van Pelt, 2009). It is important for leaders to hold employees accountable on what is accomplished in this new environment. It is impossible now to get an accurate measure of an employee's progress by observing them in the office or quickly stopping by their desk to get an update. Instead, focus on clear goals, outcomes, and timelines to gauge what is actually being accomplished (Wingard, 2020).

- Communicate effectively: Although effective communication influences all the frames, the way communication happens is a structural frame issue. A communication plan should include: (1) how to share information; (2) how much information is shared; and (3) when to communicate with others. For example, in a study done by Grenny \& Maxfield (2017), "nearly half of respondents (46\%) said the most successful managers checked in frequently and regularly with remote employees. The cadence of the check-ins varied from daily to biweekly to weekly, but they were always consistent and usually entailed a standing meeting or scheduled one-on-ones." However, this frequent communication by the leader is intended to provide space to listen, communicate trust, and help address issues, not to micromanage. This leadership practice will give you a collective sense of the challenges your team is facing and allow you to work as a team to share in the responsibility of finding solutions.

- Address technology: Technology is critical for effective leadership in the context of remote-working teams. However, one major distinction between a slow move toward one employee working from home and a mandate that all employees work from home (in a very short time frame) is the overwhelming introduction of multiple technological platforms and tools. In the initial stages of leading a remote-working team, especially in the context of a pandemic, help lessen the anxiety many employees are facing by simply selecting a few tools for everyone to use. This will allow employees to prioritize which tools they need to learn as quickly as possible to do their jobs effectively.

\section{Human Resource Frame}

The human resource frame focuses on the employee and addresses the employee's motivation and satisfaction, especially as it relates to accomplishing their work in this new remote-work environment (Bolman \& Deal, 2013). More specifically, the human resource frame emphasizes the important functions an employee's needs, feelings, prejudices, skills, and limitations may have on their success. The following best practices will help leaders address the human resource frame in a remote-work environment.

- Focus on connectedness: It can be easy to become too task-focused in the current situation, making sure to accomplish all that needs to get done in this rapid transition. Nevertheless, it is critical to make time to continue to build connections between everyone in the department or organization. Employees in remote-work situations run a greater risk of feeling overly isolated or disconnected, which can lead to lower levels of productivity and engagement (Gardner \& Matviak, 2020). As important as it is to ensure tasks are being completed, making sure everyone gets together to connect is essential. Find ways to bring your team together to continue building bonds and be with each other during a trying personal and professional time.

- Provide training and development opportunities: One quick way to get employees together and address any concerns about the skills needed to be successful in a remote-work environment is scheduling training and development opportunities for your employees. At the onset of working remotely, there may be some time to set up weekly training opportunities to keep your workers engaged and provide them with a new set of skills or resources. If done well, the online training might be just the normalcy the employees are looking for during the transition to working remotely.

- Communicating effectively: Every team member has a preferred style of communication, and this is increasingly important with a transition to working remotely. The more you are able to meet employees where they are at with their preferred communication style, the more likely they will feel supported. It is important to use all resources effectively to balance how you are communicating individually to employees and how you are communicating to your team as a whole. Do not assume that any one mode of communication is naturally accessible and preferred by all employees. When in doubt, ask each employee, and they will likely tell you what is best for casual check-ins and how they would like to communicate updates to you. 


\section{Symbolic Frame}

The symbolic frame, as it relates to working remotely, explores the influence that department or organizational culture has on the employees (Bolman \& Deal, 2013). Problems associated with the symbolic frame occur when the culture that is established and the symbols that are communicated do not represent the operation and outcomes of the remote-working environment. The following best practices allows a leader to address the symbolic elements of leading employees when working remotely.

\section{- Emphasize the unit's mission, vision, and values:} There is a reason you worked so hard on establishing the mission, vision, and values for your department or organization. Now is the time to use these statements of belief to guide both your culture and your decisionmaking process. Draw attention to these predetermined commitments during these tumultuous times. Finally, strongly encourage your employees to also let themselves be guided by the mission and values and to rally behind the vision of the organization moving forward.

- Foster a culture of interconnectedness: Fortunately, your team probably had the benefits of already creating interpersonal relationships prior to working remotely, which differs from teams that start at a distance. However, maintaining the important elements of interpersonal relationship building is important for employees working remotely. Allowing digital space for employees to catch up, chat, celebrate accomplishments/birthdays, or just discuss weekend plans is important to provide the feeling of socializing at work.

- Praise and reward to reinforce positive behavior: Find reasons to praise and reward effective remote-working behavior such as completing tasks, asking questions, or contributing to an effective work culture. By taking the time to recognize and reward employees in this new context, you will motivate them to continue to work effectively and demonstrate an example of what type of behaviors are appreciated (Sowcik, 2018). Recognizing and rewarding others can be simple and does not have to cost anything. This can be accomplished by sending an email, highlighting the employee's actions at the beginning of a meeting, or sending an actual award through the mail.

\section{Political Frame}

An organization or department can be viewed as a "coalition composed of individuals and groups with enduring differences who live in a world of scarce resources" (Bolman \& Deal, 2013, p. 209). Leadership within these coalitions utilizes power and influence to address this dynamic and obtain the resources needed to accomplish desired outcomes (Sowcik, 2017). The political frame, as it relates to leading employees, attends to the power dynamics in a landscape of scarce resources (Bolman \& Deal, 2013). The following suggestions will help leaders address the political frame in their leadership.

- Utilize diversity: Your department or organization is made up of individuals with different skillsets. Create a remote-work environment that draws on your employees' unique skillsets to positively influence the department or organization's goals. However, to get the most out of these different employees, you must create an environment that allows for different employees to contribute at different times. As Malhotra, Majchrzak, and Rosen (2007, p. 64) suggest, "most successful virtual team leaders establish a synchronous as well as an asynchronous collaboration rhythm." This provides space for employees to use the time during and between online meetings to generate ideas.

- Check yourself: Leaders must check their cognitive bias. There is a tendency for leaders to provide opportunities, assign tasks, and rely on employees who are similar to the leader (Wingard, 2020), which can leave particular groups of people feeling isolated or left out of the in-group. It is important for leaders to make conscious efforts to include and engage with all employees. One way to accomplish this effort and engagement is to use a list to keep track of the current opportunities each employee has had to contribute and the frequency of communication with the employees. This list can be used to ensure fair access across the department or organization to resources and your time.

- Provide grace: Allow your leadership default to be compassion and grace during times of chaos and uncertainty. As employees learn to change quickly to a remotework environment, provide them with the grace to take chances and make mistakes. The more you provide them grace for their transition to working in this new context, the more likely they are to provide you with the grace to lead them through this change and beyond.

\section{Conclusion}

Leading teams in a remote-work setting can be thrust upon you and your unit, regardless of whether you are ready during times of a disaster. It can be a complex and confusing time when leaders turn to their perceptions of leading in traditional settings to guide their leadership in a newly remote context. This can lead to problems both with task completion and employee engagement. However, 
your ability to effectively lead your team does not have to diminish because of the change in work setting. By addressing the four frames of leadership, you can quickly put into place the necessary processes to lead a highly functioning remote-work team.

\section{References}

Astashkina, J. (2005). Working with virtual teams. MultiLingual Computing \& Technology, 16(7), 15-66.

Bolman, L. G., \& Deal, T. E. (2013). Reframing organizations: Artistry, choice, and leadership. John Wiley \& Sons.

Gardner, H. K., \& Matviak, I. (2020). Coronavirus could force teams to work remotely. Harvard Business Review. https://hbr.org/2020/03/ coronavirus-could-force-teams-to-work-remotely

Grenny, J., \& Maxfield, D. (2017). A study of 1,100 employees found that remote workers feel shunned and left out. Harvard Business Review. https://hbr.org/2017/11/astudy-of-1100-employees-found-that-remote-workers-feelshunned-and-left-out

Malhotra, A., Majchrzak, A., \& Rosen, B. (2007). Leading virtual teams. Academy of Management Perspectives, 21(1), 60-70.

Sowcik, M., Carter, H., \& McKee, V. (2017). Reframing leadership. AEC622. Gainesville: University of Florida Institute of Food and Agricultural Sciences. https://edis.ifas. ufl.edu/wc284

Sowcik, M., Carter, H., \& McKee, V. (2018). Reframing recognition. AEC662. Gainesville: University of Florida Institute of Food and Agricultural Sciences. https://edis.ifas. ufl.edu/wc325

Van Pelt, S. (2009). The complexities of leading virtual teams: A phenomenological study [Doctoral dissertation, University of Phoenix]. Proquest. https://search.proquest. com/docview/305123168?pq-origsite=gscholar

Wingard, J. (2020). Leading remote workers: The Coronavirus' impact on effective management. Forbes. https://www. forbes.com/sites/jasonwingard/2020/03/13/team-workingat-home-because-of-coronavirus-heres-how-to-lead-themeffectively/ 